\title{
FOLLOWING THE “WHY? WHAT? AND HOW?” SCHEMA TO IMPROVE ROAD-KILL EVALUATION IN ENVIRONMENTAL IMPACT ASSESSMENTS OF SOUTHERN BRAZIL
}

\author{
Andreas Kindel ${ }^{1,2 *}$, Fernanda Zimmermann Teixeira ${ }^{1,3}$, Larissa Oliveira Gonçalves ${ }^{1,2}$, Igor Pfeifer \\ Coelho $^{1,2}$, Júlia Beduschi ${ }^{1,2}$, Gabriela Schuck de Oliveira1 ${ }^{1}$, Carolina A. Lemos ${ }^{4}$, Carmen Zotz \\ Herkenhoff', Mozart Lauxen ${ }^{4}$, Luiz Carlos de Lima Leite ${ }^{5}$, Luis Fernando dos S. Silveira ${ }^{5}$, \\ Sergio Augusto Pereira da Silva ${ }^{6}$ \& Dênis Alécio Sana
}

\begin{abstract}
${ }^{1}$ Universidade Federal do Rio Grande do Sul (UFRGS), Instituto de Biociências, Departamento de Ecologia, Núcleo de Ecologia de Rodovias e Ferrovias (NERF). Av. Bento Gonçalves, 9500, Setor IV, Prédio 43411, sala 207, Porto Alegre, RS, Brasil. CEP: $91501-970$ ${ }^{2}$ Universidade Federal do Rio Grande do Sul (UFRGS), Instituto de Biociências, Departamento de Ecologia, Programa de Pós-Graduação em Ecologia. Av. Bento Gonçalves, 9500, Setor IV, Prédio 43422, sala 102, Porto Alegre, RS, Brasil. CEP: $91501-970$

${ }^{3}$ Carleton University, Geomatics and Landscape Ecology Research Laboratory, Nesbitt Biology Bldg. 1125 Colonel By Drive, Ottawa, ON, Canada, K1S 5B6

${ }^{4}$ Instituto Brasileiro do Meio Ambiente e dos Recursos Naturais Renováveis (IBAMA), Núcleo de Licenciamento Ambiental, Superintendência Estadual do IBAMA/RS. Rua Miguel Teixeira, 126, Porto Alegre, RS, Brasil. CEP: 90050-250

${ }^{5}$ Departamento Autônomo de Estradas de Rodagem (DAER-RS). Av. Borges de Medeiros, 1555, Porto Alegre, RS, Brasil. CEP: $90020-020$

${ }^{6}$ Fundação Estadual de Proteção Ambiental Henrique Luis Roessler (FEPAM). Av. Borges de Medeiros, 261, Porto Alegre, RS, Brasil. CEP: 90020-021

${ }^{7}$ Secretaria do Ambiente e Desenvolvimento Sustentável do Rio Grande do Sul (SEMA), Departamento de Biodiversidade, Setor de Fauna. Av. Borges de Medeiros, 261, Porto Alegre, RS, Brasil. CEP: 90020-021

E-mails: andreaskindel@gmail.com,_fernandazteixeira@gmail.com, larissa.oligon@gmail.com, djakare@gmail.com, julia.beduschi@gmail.com,gaby.schuck@hotmail.com, carolina.lemos@ibama.gov.br, carmen.herkenhoff@ibama.gov.br, mozart.lauxen@ibama.gov.br,luizcl@daer.rs.gov.br,luisfs@daer.rs.gov.br,sergaps@terra.com.br,denis-sana@uol.com.br
\end{abstract}

\begin{abstract}
Environmental licensing is one of the most important tools of environmental policies in any country, as it allows to adopt preventive and mitigation measures on predicted or observed environmental impacts. However, Environmental Impact Assessments are recurrently criticized due to their low quality and effectiveness to support decisions for project viability or mitigation planning. One way to counteract those limitations is by strengthening terms of reference. Here we present the results of a collaborative initiative carried out in southernmost state of Brazil to improve terms of reference for assessments of vertebrate road mortality in a context of road widening. This initiative integrated contributions from stakeholders involved in road planning, construction, operation and road environmental assessments and licensing through a series of workshops undertaken during two years. Using the Why, What and How schema, we first briefly present the reasons to evaluate wildlifevehicle collisions in environmental assessments, and then we comment some limitations of current legal regulations and environmental impact assessments in Brazil and identify the improvements needed. We describe the approach and principles used to develop a sampling protocol for what and how to sample and how to analyze vertebrate road mortality data in Brazilian roads. Finally, we present the result of this effort, the guidelines itself. Although focused on a single road impact (road-kill), we expect that our approach could be replicated to produce guidelines to improve assessments of other road impacts and even other types of infrastructures or activities for which environmental licensing is a pre-requisite.
\end{abstract}

Keywords: environmental licensing; road mortality; sampling protocol; scoping; wildlife-vehicle collisions.

\section{INTRODUCTION}

Environmental licensing is one of the most important tools of environmental policies in any country (Lawrence 2003), since it has the aim of preventing or minimizing environmental impacts of individuals, corporations or state activities. Licensing through Environmental Impact Assessments (EIAs), or other simplified study versions, is established in most countries, and is a mandatory pre-requisite for activities with potential impacts ranging from local (e.g., land use division for housing) to global scale (e.g. nuclear plants) (Abaza et al. 2004). Although there are other planning instruments enforced in environmental legislation of most countries (e.g., ecological zoning, strategic environmental assessment), EIAs are the only 
land use planning tool that follows the entire mitigation hierarchy, that is, avoiding, minimizing, mitigating and compensating impacts (Chee 2015).

EIAs have been criticized by their low quality and low effectiveness to avoid or mitigate environmental impacts (Lawrence 1997, Jaeger 2015). The quality is related to study inputs (adequacy of methods, data, and analysis), while effectiveness is related to outputs (direct and indirect consequences of the licensing process, Lawrence 1997). Usually, studies do not include good assessment and prediction of potential environmental impacts of an activity (Jaeger 2015), often apply inadequate methodological approaches for evaluated impacts, and rarely have influence on decision making (Karlson et al. 2014).

Strengthening and enforcing of regulations are recognized as a way of increasing EIA quality and effectiveness (Landim \& Sánchez 2012). Among regulations, there is the requirement of a Term of Reference (ToR) to define how EIA should be performed, establishing the scope of the study and, usually, presenting the guidelines of what and how data should be collected. The ToR has the status of a legal step in each licensing process that should be attended by every stakeholder, but it is a technical and relatively flexible document, with scope and procedures defined by the Environmental Agency frequently in collaboration with consultants. ToR can be adapted to different contexts according to the type and size of the activity, its location and potential impacts. ToR can be continually revised, following novel or revised scoping approaches (Hansen \& Wood 2016) and new knowledge or new technologies made available.

Improvement of ToR should be promoted by the integration and collaboration of all involved stakeholders: road builders and planners, environmental and regulating agencies, environmental consultants and researchers (Teixeira et al. 2016). Here we present the results of an experience carried out in Rio Grande do Sul State, southern Brazil, to improve the quality of ToR focusing on the wildlife-vehicle collisions impact of road widening projects. Following the Why-WhatHow schema, we present the reasons to assess road mortality and current limitations of EIAs for roads. Then, we describe our approach to build improved ToR for vertebrate road mortality assessments, and present the recommendations for a new sampling protocol.

Why-what-how schema

Any data collection should be preceded by a planning step structured in three fundamental questions: "Why?", "What?", and "How?" (Yoccoz et al. 2001, Ferraz 2012). Many environmental studies fail to clearly state their goals, and the definition of the aims of a study (Why?) need to be related to the management options available and the hypothesis of how the system respond to project activities (Mackenzie et al. 2006). After clearly stating why data should be collected to address specific questions, one can decide what data should be collected in an environmental study (What?). The decision of "what" depends on which systems need to be described and on the different management possibilities. Only then it is possible to define the methodological procedures for data collection and analysis (How?) (Mackenzie et al. 2006).

\section{Why is road mortality important?}

Road mortality from wildlife-vehicle collision is a major impact of roads on wildlife (Forman et al. 2003), and should be mitigated for different reasons (adapted from Seiler \& Helldin 2006):

1) Ethics: Ethical issues involving animal care and the recognition of the intrinsic values of every species has a legal support on the Environmental Crimes Law in Brazil (DOU 1998). Traffic is responsible for road mortality of a large number of species, from invertebrates (Muñoz et al. 2015) to vertebrates (Trombulak \& Frissell 2000), including domestic and wild animals. For ethical reasons, mitigation measures can be planned aiming to decrease or eliminate animal-wildlife collisions of every species.

2) Safety: Animal-vehicle collisions can cause huge economic losses (e.g., 4 billion dollars estimated in costs to insurance companies due to deer-vehicle collisions in USA in 2011-2012; Cramer et al. 2015) and many human injuries and losses of lives. Based on online news, Freitas \& Barszcz (2015) recorded 66 human deaths from wildlife-vehicle collisions on Brazilian roads between 2007 and 2012, which is already a high number although strongly 
underestimated. Concerns about human safety and economic losses justify the identification of high-risk species, such as large mammals, for mitigation prioritization (Huijser et al. 2009, Huijser et al. 2013). However, vehicle collisions with small-sized species, such as birds being hit by the windshield, might cause serious accidents as well, depending on driver reaction.

3) Conservation: Road mortality may decrease population viability of some species due to abundance (Fahrig \& Rytwinski 2009) and genetic diversity reduction (Jackson \& Fahrig 2011). Some species are more prone to road mortality than others and can be prioritized for mitigation, for example, species that do not avoid vehicles or species with higher mobility and lower reproduction rates (Rytwinski \& Fahrig 2011). Miotto et al. (2012) provided a dramatic example of a species threatened by roads to be prioritized in the fragmented Atlantic Forest, Puma concolor, although the prediction of locations with higher mortality probability for this species is challenging.

Considering the need to mitigate road mortality based on the reasons above, data on road mortality can and should be used to plan mitigation measures. Data on which species are road-killed, estimates of mortality magnitude and information of spatial and temporal patterns are relatively easy to access and should be used to support decision making about the necessity of mitigation as well as to decide type and location for selected measures.

What should be improved in road-kill assessments?

EIAs using data collected and analyzed properly have a higher probability to result in evidence-based decision making. When there is no data or low quality data, mitigation proposition is based on the opinion of environmental consultants or literature extrapolations, rarely linked to the information produced by the study. Studies of low quality will result in low effectiveness of decision making, and consequent environmental damage and economic waste.

Some authors document the low quality and low effectiveness of EIAs for roads. The main critics are related to: the lack of methodological details, gaps in covered impacts on biodiversity, poor consideration of the effects of fragmentation and barrier, emphasis on descriptive approaches instead of using analytical or predictive models, and poor assessment of indirect and cumulative impacts (Karlson et al. 2014, Jaeger 2015). In the case of road mortality evaluation, EIAs usually fail by not answering the fundamental questions to measure the magnitude of this impact (Which? How many?) and to guide adequate mitigation measures (When? Where?).

Methodological problems in study design can make it impossible to compare data collected before and after the impact or the mitigation (Roedenbeck et al. 2007). Analytical problems are also common, such as not considering bias (e.g., mortality estimates corrected for carcass removal and detection, Teixeira et al. 2013b), or using analyses with low power and without indication of uncertainty (Tennøy et al. 2006).

\section{How assessments could be improved?}

To change this scenario of poor quality in EIAs, we need to modify the rationale and order of its structure (Ferraz 2012). Nowadays, most of Brazilian EIAs still start with the extensive description of the biotic and abiotic attributes of the area that will be impacted, the so called baseline studies. This is followed by identification of potential impacts, a practice certainly rooted on the beginnings of environmental assessments in the 1980s. However, standard best practice recognized scoping as a key step long ago, previous to ToR, focusing on priority potential impacts (IAIA 1999). This principle was fully recognized and developed in the "Voluntary guidelines on biodiversity-inclusive impact assessment", a COP8 decision (CBD 2006). We recommend that data collection and analysis for EIA urgently should follow these principles and guidelines particularly valuing the scoping process, with key study issues oriented directly from expected impacts. In the specific case of road widening and the risk of vertebrate mortality increase, we propose that the baseline studies are guided, at least, by the fundamental questions to describe the current mortality pattern: "Which animals are being road-killed?", "How many individuals are road-killed?", "Where are the road-kills occurring?" and "When are the road-kills occurring?". 
Answering these questions is crucial to determine if there is an impact high enough to be of concern and, if yes, to orient mitigation planning and its effectiveness monitoring. Identifying which species are being road-killed allows identifying if road mortality should be a concern for driver safety or for population persistence of those species, besides informing which specific type of mitigation could be better. Estimating road mortality magnitude will be needed for before and after comparisons, including before and after the impact (road widening) or before and after mitigation implementation. Also, if data on population abundance is available, the effect of mortality magnitude on population persistence can be assessed. Finally, identifying the locations and periods with higher mortality may indicate where and when mitigation should be prioritized. Although most mitigation structures, like underpasses and overpasses, are spatially static, speed reducers could be spatially changed, and speed controllers, traffic calming, road closure or even small animal driving fences could be programmed for specific time windows.

This proposed change in the rationale of EIAs is based on two principles:

First Principle - EIAs should describe the likely future state of an area, with and without the proposed project, by estimating the magnitude (intensity, location, extent, frequency, and duration) of environmental changes resulting from the expected impact drivers. This means that assessments should be directed by stated questions connected to available management decisions for each impact, fully recognizing the mitigation hierarchy (Chee 2015). Defining or standardizing methods for data collection or metrics to be used only makes sense after stating the questions that need to be answered by the EIA (Ferraz 2012, Yoccoz et al. 2001).

Second Principle - Every environmental licensing process should be faced as an experiment, as a way of answering questions and testing hypothesis about the potential impacts using scientific rigor in defining the variables to be measured. The use of appropriate study designs increases the EIA influence on decision making related to the activity under environmental licensing and other licensing process as well (Rytwinski et al. 2015).
Beanlands \& Duinker (1983) described reasoning and suggestions for appropriate scoping and study strategies considering these kinds of principles more than three decades ago. According to our experience, these two principles are rarely followed in Brazilian EIAs, although they are implicit in the environmental legislation in Brazil (CONAMA 1986).

\section{MATERIAL AND METHODS}

Between November 2013 and December 2015, we carried out a series of six workshops involving the Rio Grande do Sul State (FEPAM-RS) and the federal (IBAMA-RS) environmental licensing agencies, the road state agency (DAER-RS), the state environment secretary (Setor de Fauna, Secretaria Estadual do Ambiente e Desenvolvimento Sustentável, SEFAU-SEMA), researchers on road ecology from the university (Núcleo de Ecologia de Rodovias e Ferrovias, NERF-UFRGS), and environmental consultants experienced in EIAs of roads. The discussions during the workshops were based on the Normative Instruction issued by the federal environmental agency IN IBAMA 13/2013 (MMA 2013), which establishes the procedures for methodological standardization of wildlife sampling in environmental licensing of roads and railroads. The Normative Instruction itself states that the recommended procedures should be revised, which has started to be discussed in a national level (a workshop was carried out during the conference Road Ecology Brazil in 2014, and the results are available at https://issuu.com/portal.cbee/docs/ workshop_reb_2014). Furthermore, the sampling protocol established by the Normative Instruction is not adopted by the state environment agency, so this debate is needed in a local level as well.

To involve and motivate everyone in the discussion process and increase the productivity of the workshops, we adopted the following strategies:

1) Two-step discussions: in the first step we had five meetings including researchers and technicians from the state road agency and from the environmental agencies (state and federal). The product of these meetings was the first version of the sampling protocol 
that was then discussed, in a second step, in a meeting involving a large group of environmental consultants, after they had accessed the document.

2) Meetings in 4h-shifts: we restricted the duration of the meetings to guarantee the presence of all professionals involved during all discussions. To ensure the productivity in this short $4 \mathrm{~h}$-shift we previously defined the subjects to be discussed involving only one study question per meeting, we applied facilitation rules to the meetings, and we made available the memories of previous meetings to avoid returning to previously discussed topics.

3) Different workshop locations: each meeting was carried in a different institution among the institutions participating in the discussions. We made this to enforce the involvement of participants and to stimulate the institutional recognition of individuals' participation in the process, increasing the probability of our recommendations being enforced by these institutions.

We believe that three elements should be explicitly present in any ToR, or at least in the technical documents supporting sampling protocols. We made an attempt to include them explicitly in our recommendations:

1) Questions to be answered in the EIA;

2) Justification for each question: the number of interesting questions in environmental studies is almost infinite, but the First Principle (see above) should not be forgotten: the stated questions should be directed by the management options available during the licensing process, from the viability of the activity to how impacts that cannot be mitigated should be compensated, respecting the mitigation hierarchy;

3) Supporting evidence for the methods and analysis recommendations: the recommendations presented in a sampling protocol should not be seen as a definitive or rigid protocol. There are many different approaches to describe and seek for explanations for nature phenomena and which one will be used can be a subjective choice. This is the reason why the supporting evidence for methodological decisions should be stated and justified based on literature, when possible.

\section{RESULTS AND DISCUSSION}

In this paper, we recommend a protocol for sampling road mortality to be incorporated in TRs of environmental impact assessment of road widening. The recommendation was built in Rio Grande do Sul with the collaboration of different professionals (academia, environmental agencies, road agency, and environmental consultants), and can be replicated in other regions. We summarize the workshop results (Table 1), presenting a sampling protocol recommended for studies developed for the Previous Environmental License (which attests the viability of the project) and for the Installation Environmental License (which allows construction to begin) in cases of road widening. Adaptations are needed for other contexts (Operation License or other cases such as road construction or paving), although many of the questions would be the same.

Good scientific basis may be lacking for some recommendations of approaches, methods, or variables. Our discussion exercise, along with the proposed guidelines highlighted a number of methodological knowledge gaps that should be filled to further qualify decision making. We encourage collaboration between academia, environmental agencies and consultants to address these questions by testing new methods and approaches during the licensing (Second Principle).

When long road segments are under survey, is carcass detection affected by observers' fatigue or other spatially structuring effect? Although the detection error as well the carcass persistence error can be corrected to estimate mortality magnitude, spatial patterns and even road-killed assemblage might be biased if significant spatial differences in detectability and persistence are found. Do we need to survey the entire road or can we sample random segments to estimate road-kill magnitude? This extrapolation might be valid when focusing on a species or group of species with clear habitat affinities. If this is the case, efforts can be optimized by monitoring random road segments and extrapolating the results to the entire road network. 


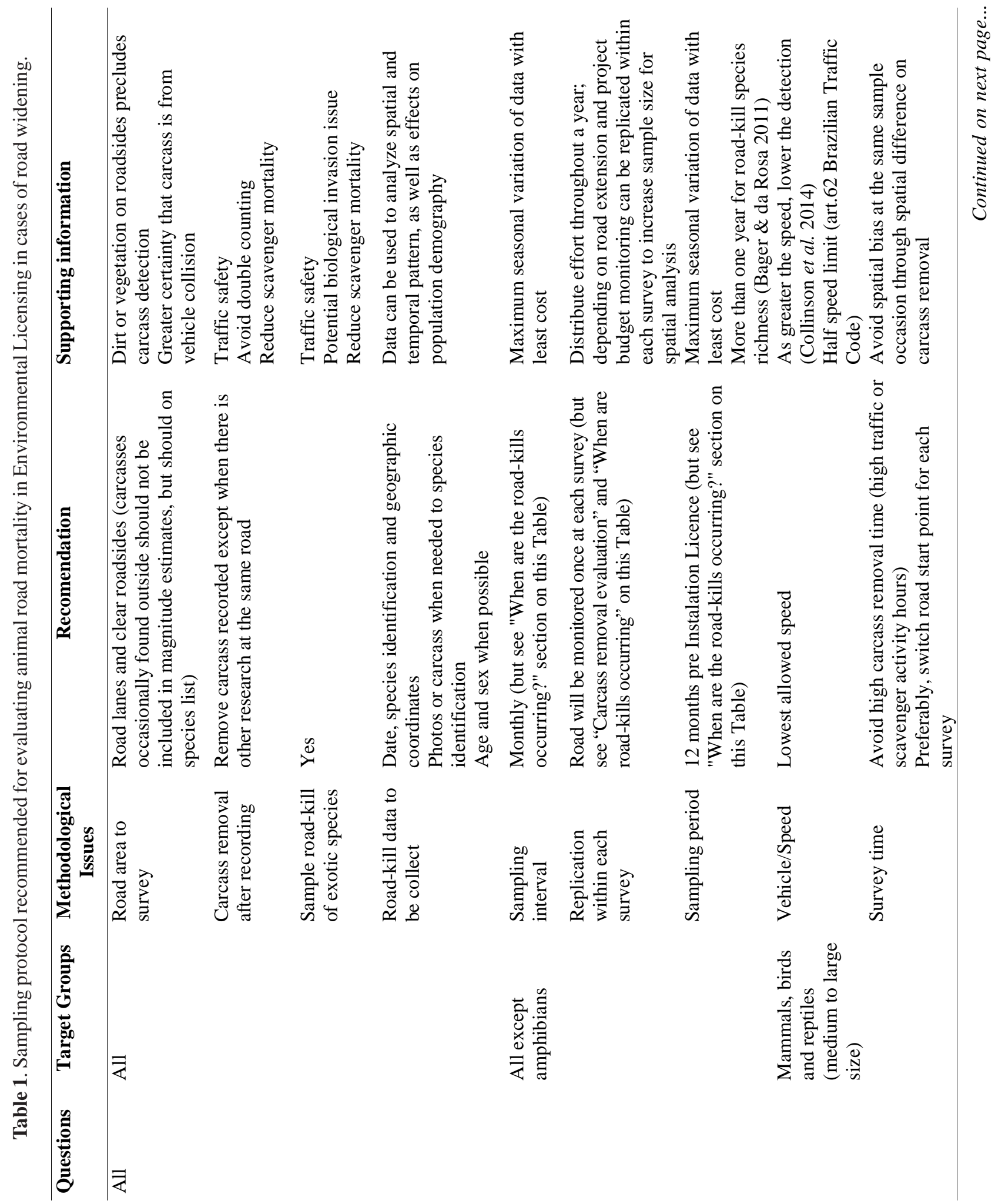




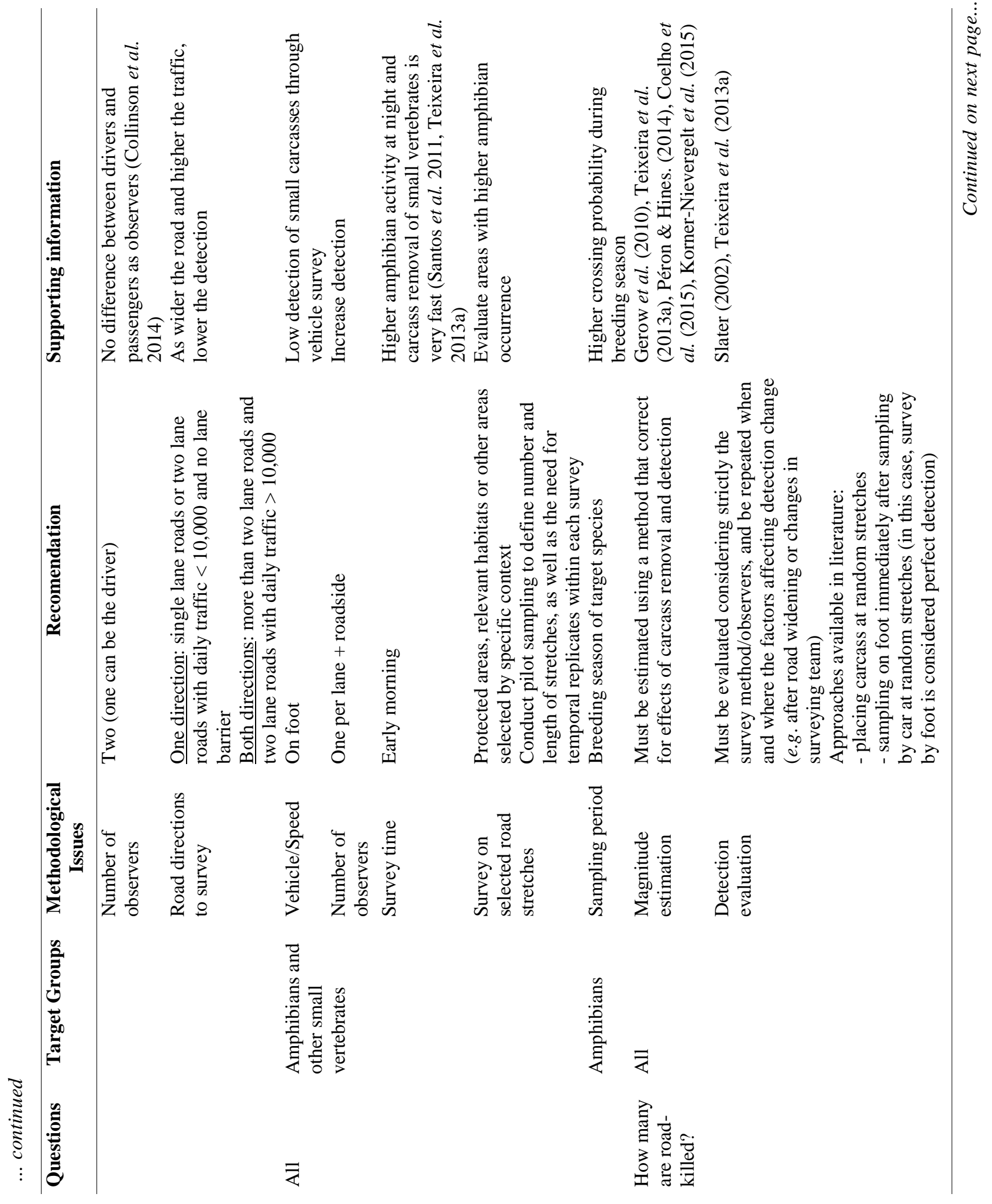




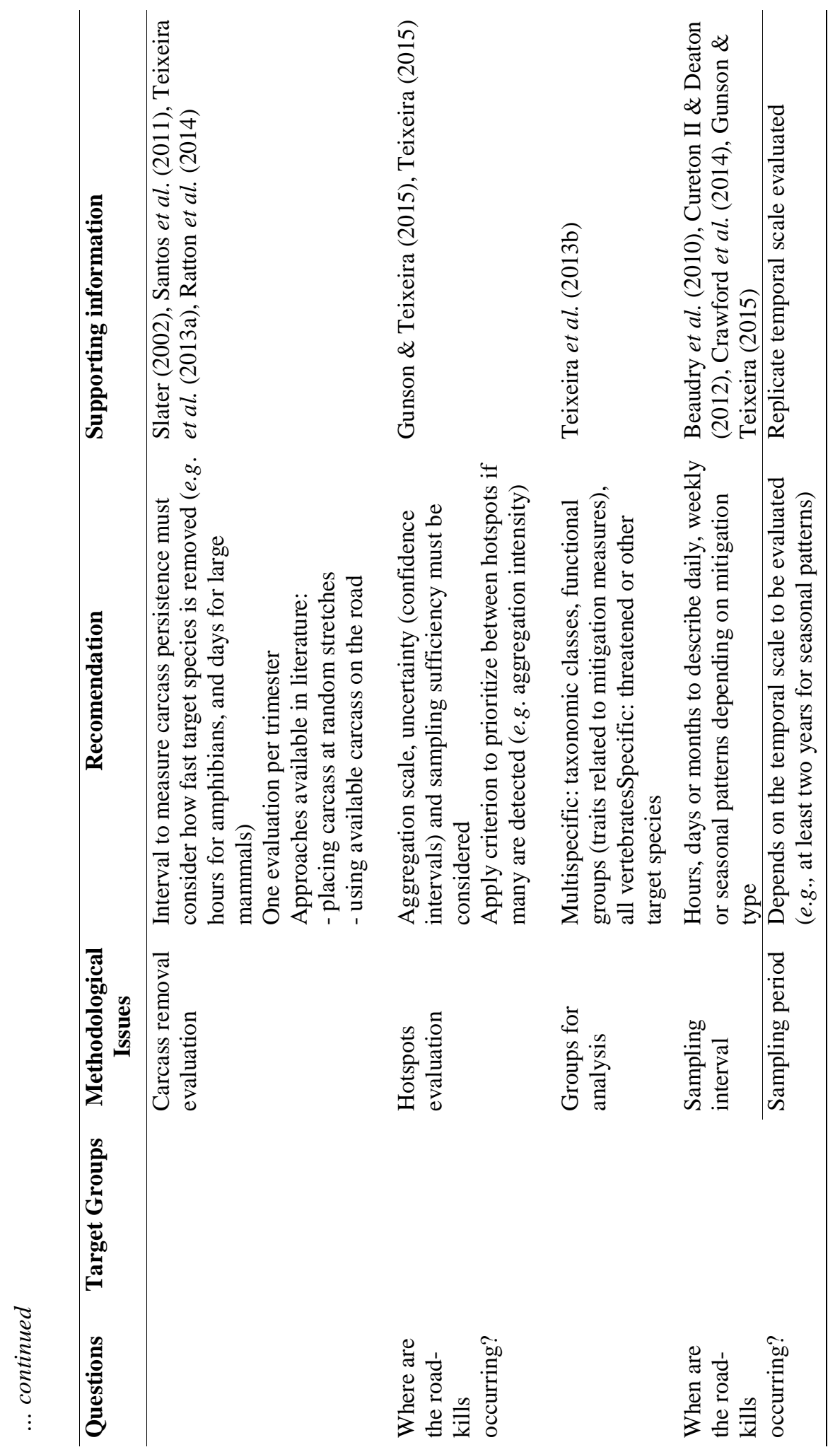


Other methodological questions may arise related to the effects of frequency and intensity of monitoring. Can we concentrate road-kill monitoring in only one period of the year? Sampling frequency and intensity have consequences for the estimates of mortality magnitude (by sampling in the period when animals are more or less active) and for detecting spatial and temporal patterns (minimum sampling effort to detect these patterns). These effects can be tested by simulating the effects of different sampling frequencies and intensities upon different metrics (mortality magnitude, hotspots location) using available datasets. Rosa \& Bager (2012) demonstrate that bird mortality was concentrated in the summer and autumn in southern Brazil, and Coelho et al. (2012) showed that amphibian mortality was concentrated in spring. Reduction of survey costs and time for decision making might be obtained by concentrating monitoring in a short period, but the effects of intensive monitoring in one season on the patterns detected should still be tested. Santos et al. (2011) recommended daily monitoring to counteract low detectability of small mammals, amphibians and birds, but Snow et al. (2015) suggests that undersampling of large mammals do not affect predictive models.

We focused on vertebrate road mortality, but invertebrate road-kills should also be evaluated when though to be relevant. Several studies have been documenting evidences of severe reduction in insect populations due to road mortality, which may have potential effects in ecological processes such as pollination (Muñoz et al. 2015).

Our guidelines explore the most fundamental questions related to identifying and describing road mortality on a road. However, the effect of such mortality on populations (Roedenbeck et al. 2007, Stokes 2015) or the explanations for mortality magnitude and spatial and temporal patterns are other questions that should be incorporated in the future (Gunson et al. 2011). Although we focused on mortality, the same principles and approach (workshops) presented here might be replicated to improve the assessment of other road impacts in EIAs, such as direct or indirect habitat loss or habitat degradation by noise (Trombulak \& Frissell 2000, Forman et al. 2003).
A challenging issue is how to plan vertebrate mortality avoidance and mitigation in new road projects, since there are no road-kill data. Predictive modeling is an available tool (Gunson et al. 2011) and new road projects should be used as experiments to test and validate it. We call for an urgent cooperation between all stakeholders for scoping and recommending procedures for this type of studies. We suggest that our workshop approach is a way to compromise all involved institutions and technicians with that task.

We recommend changes in ToR for road widening projects, but the improvements on data collection and analysis for assessing, avoiding and mitigating impacts of roads should be incorporated in other environmental planning policies as well. That is the case of studies carried out by the Brazilian road and railway department (DNIT - Departamento Nacional de Infraestrutura de Transportes) to assess the technical, economic and environmental viability of projects before applying to environmental licenses (called EVTEA -Estudos de Viabilidade Técnica, Econômica e Ambiental), or other tools for Strategic Environmental Assessment (SEA) at a single or road network levels. In the context of SEA, the structure of studies oriented by questions about the potential impacts should be adopted, incorporating assessment of the cumulative impacts and of fragmentation caused at the landscape scale (Jaeger 2015).

Our goal was to illustrate a possible way of improving the quality and effectiveness of environmental licensing, presenting as a result a sampling protocol to guide how to answer the fundamental questions in EIAs for roads. The success of our approach depends on the recognition that knowledge is dynamic and the definition of these protocols should be carried out following an adaptive management approach, with periodic revisions of successes and failures, and the incorporation of new methodological approaches (Noble 2000, MorrisonSaunders \& Art 2004).

\section{ACKNOWLEDGMENTS}

We thank Cristiane Ottes Vargas for participating in workshop discussions, as well as all the environmental consultants that discussed the recommended sampling protocol. We also thank Karoline Pacheco Abilhôa Freitas and three anonymous reviewers 
for their comments and suggestions to a previous version of this manuscript.

\section{REFERENCES}

Abaza, H., Bisset, R., \& Sadler, B. 2004. Environmental impact assessment and strategic environmental assessment: towards an integrated approach. 1st ed. Châtelaine, GVA: United Nations Environment Programme: p. 147.

Bager, A., \& da Rosa, C. A. 2011. Influence of sampling effort on the estimated richness of road-killed vertebrate wildlife. Environmental Management, 47(5), 851-858. DOI: 10.1007/ s00267-011-9656-x

Beanlands, G. E., \& Duinker, P. N. 1983. An ecological framework for environmental impact assessment in Canada. ISBN o7703-0460-5; p. 127. Halifax: Institute for Resource and Environmental Studies. Retrieved from www.epe.lac-bac.gc.ca/ 100/200/301/ceaa-acee/ecological_framework-e/23E.PDF

Beaudry, F., Demaynadier, P. G., \& Hunter, M. L. 2010. Identifying hot moments in road mortality risk for freshwater turtles. The Journal of Wildlife Management, 74(1), 152-159. DOI: $10.2193 / 2008-370$

CBD - Convention on Biological Diversity. 2006. COP8 Decision VII/28. Impact Assessment: Voluntary guidelines on biodiversity-inclusive impact assessment. Retrieved from: www.cbd.int/doc/decisions/cop-08/cop-08-dec-28-en.pdf

Chee, Y. E. 2015. Principles underpinning biodiversity offsets and guidance on their use. In: R. van der Ree, D. J. Smith \& C. Grilo (Eds.), Handbook of road ecology. pp. 51-59. West Sussex: John Wiley \& Sons.

Coelho, I. P., Teixeira, F. Z., Colombo, P., Coelho, A. V. P., Kindel, A. 2012. Anuran road-kills neighboring a peri-urban reserve in the Atlantic Forest, Brazil. Journal of Environmental Management, 112, 17-26. DOI: 10.1016/ j.jenvman.2012.07.004

Coelho, A. V. P., Coelho, I. P., Teixeira, F. T., Kindel, A. 2015. Siriema: road mortality software. User's Manual V. 2.0. NERF, UFRGS, Porto Alegre, Brazil. Retrieved from www.ufrgs.br/ siriema

Collinson, W. J., Parker, D. M., Bernard, R. T. F., Reilly, B. K., Davies-Mostert, H. T. 2014. Wildlife road traffic accidents: a standardized protocol for counting flattened fauna. Ecology and Evolution, 4(15), 3060-3071. DOI: 10.1002/ece3.1097

CONAMA - Conselho Nacional do Meio Ambiente. 1986. Resolução CONAMA n 1 , de 23 de janeiro de 1986. Publicada no DOU, de 17 de fevereiro de 1986, Seção 1, p. 2548-2549.

Cramer, P., Olsson, M., Gadd, M. E., van der Ree, R., Sielecki, L. E. 2015. Transportation and large herbivores. In: R. van der Ree, D. J. Smith \& C. Grilo (Eds.). Handbook of road ecology. pp. 344-352. West Sussex: John Wiley \& Sons.

Crawford, B. A, Maerz, J. C., Nibbelink, N. P., Buhlmann, K. A., Norton, T. M., Albeke, S. E. 2014. Hot spots and hot moments of diamondback terrapin road-crossing activity. Journal of Applied Ecology, 51(2), 367-375. DOI: 10.1111/13652664.12195

Cureton II, J. C., \& Deaton, R. 2012. Hot moments and hot spots: identifying factors explaining temporal and spatial variation in turtle road mortality. The Journal of Wildlife Management, 76(5), 1047-1052. DOI: 10.1002/jwmg.320

DOU - Diário Oficial da União. 1998. Lei Nº 9.605, de 12 de fevereiro de 1998. Publicada no DOU, de 13 de fevereiro de 1998, p.1.

Fahrig, L., \& Rytwinski, T. 2009. Effects of roads on animal abundance/ : an empirical review and synthesis. Ecology and Society, 14(1), 21.

Ferraz, G. 2012. Twelve guidelines for biological sampling in environmental licensing studies. Natureza \& Conservação, 10(1), 20-26. DOI: 10.4322/natcon.2012.004

Forman, R. T. T., Sperling, D., Bissonete, J. A., Clevenger, A. P., Cutshall, C. D., Dale, V. H., Fahrig, L., France, R., Goldman, C. R., Heanue, K., Jones, J. A., Swanson, F. J., Turrentine, T., Winter, T. C. 2003. Road ecology: science and solutions. 2nd ed. Washington, DC: Island Press: p. 504.

Freitas, S. R., \& Barszcz, L. B. 2015. A perspectiva da mídia online sobre os acidentes entre veículos e animais em rodovias brasileiras: uma questão de segurança? Desenvolvimento e Meio Ambiente, 33, 261-276. DOI: 10.5380/dma.v33i0.36910

Gerow, K., Kline, N. C., Swann, D. E., Pokorny, M. 2010. Estimating annual vertebrate mortality on roads at Saguaro National Park; Arizona. Human-Wildlife Interactions, 4(2), 283-292.

Gunson, K. E., Mountrakis, G., \& Quackenbush, L. J. 2011. Spatial wildlife-vehicle collision models: a review of current work and its application to transportation mitigation projects. Journal of Environmental Management, 92(4), 1074-1082. DOI: 10.1016/j.jenvman.2010.11.027

Gunson, K., \& Teixeira, F. Z. 2015. Road-wildlife mitigation planning can be improved by identifying the patterns and processes associated. In: R. van der Ree, D. J. Smith \& C. Grilo (Eds.), Handbook of road ecology. pp. 101-109. West Sussex: John Wiley \& Sons.

Hansen, E., \& Wood, G. 2016. Understanding EIA scoping in practice: A pragmatist interpretation of effectiveness. Environmental Impact Assessment Review, 58, 1-11. DOI: 10.1016/j.eiar.2016.01.003

Huijser, M. P., Duffield, J. W., Clevenger, A. P., Ament, R. J., McGowen, P. T. 2009. Cost-benefit analyses of mitigation measures aimed at reducing collisions with large ungulates in the United States and Canada: A decision support tool. Ecology and Society, 14(2), 15.

Huijser, M. P., Abra, F. D., \& Duffield, J. W. 2013. Mammal road mortality and cost - benefit analyses of mitigation measures aimed at reducing collisions with capybara (Hydrochoerus hydrochaeris) in São Paulo State, Brazil. Oecologia Australis, 17(1), 129-146. DOI: 10.4257/oeco.2013.1701.11

IAIA - International Association for Impact Assessment. 1999. Principles of Environmental Impact Assessment best practice. Retrieved from www.iaia.org/best-practice.php

Jackson, N. D., \& Fahrig, L. 2011. Relative effects of road mortality and decreased connectivity on population genetic diversity. Biological Conservation, 144(12), 3143-3148. DOI: 10.1016/j.biocon.2011.09.010

Jaeger, J. A. G. 2015. Improving environmental impact assessment and road planning at the landscape scale. In: R. van der Ree, 
D. J. Smith \& C. Grilo (Eds.), Handbook of road ecology. pp. 32-42. West Sussex: John Wiley \& Sons.

Karlson, M., Mörtberg, U., \& Balfors, B. 2014. Road ecology in environmental impact assessment. Environmental Impact Assessment Review, 48, 10-19. DOI: 10.1016/ j.eiar.2014.04.002

Korner-Nievergelt, F., Behr, O., Brinkmann, R., Etterson, M. A., Huso, M. M. P., Dalthorp, D., Korner-Nievergelt, P., Roth, T., Niermann, I. 2015. Mortality estimation from carcass searches using the R-package carcass - a tutorial. Wildlife Biology 21(1), 30-43. DOI: 10.2981/wlb.00094

Landim, S. N. T., \& Sánchez, L. E. 2012. The contents and scope of environmental impact statements: how do they evolve over time? Impact Assessment and Project Appraisal, 30(4), 217228. DOI: $10.1080 / 14615517.2012 .746828$

Lawrence, D. P. 1997. Quality and effectiveness of environmental impact assessments: lessons and insights from ten assessments in Canada. Project Appraisal, 12(4), 219-232. DOI: 10.1080/ 02688867.1997.9727064

Lawrence, D. P. 2003. Environmental impact assessment: practical solutions to recurrent problems. 1st ed. Hoboken, NJ: John Wiley \& Sons: p. 576.

Mackenzie, D. I., Nichols, J. D., Royle, J. A., Pollock, K. H., Bailey, L. I., Hines, J. E. 2006. Occupancy estimation and modeling - Inferring patterns and dynamics of species occurrence. 1st ed. Burlington, MA: Elsevier: p. 343.

Miotto, R. A., Cervini, M., Begotti, R. A., Galetti Jr, P. M. 2012. Monitoring a puma (Puma concolor) population in a fragmented landscape in southeast Brazil. Biotropica, 44(1), 98-104. DOI: 10.1111/j.1744-7429.2011.00772.x

MMA - Ministério do Meio Ambiente. 2013. Instrução Normativa. $n^{\circ} 13$, de 19 de julho de 2013. Publicada no DOU, de 23 de julho de 2013, Seção 1, p. 62.

Morrison-Saunders, A., \& Arts, J. (Eds.). 2004. Assessing impact - handbook of EIA and SEA follow-up. Vancouver: Earthscan: p. 338.

Muñoz, P. T., Torres, F. P., \& Megías, A. G. 2015. Effects of roads on insects: a review. Biodiversity and Conservation, 24(3), 659-682. DOI: 10.1007/s10531-014-0831-2

Noble, B. F. 2000. Strengthening EIA through adaptive management. Environmental Impact Assessment Review, 20(1), 97-111. DOI: 10.1016/S0195-9255(99)00038-4

Péron, G., \& Hines, J. E. 2014. fatalityCMR—capture-recapture software to correct raw counts of wildlife fatalities using trial experiments for carcass detection probability and persistence time. Techniques and Methods 7-C11; p. 22. Virginia: U.S. Department of the Interior, U.S. Geological Survey and U.S. Fish and Wildlife Service. Retrieved from www.pubs.usgs.gov/ tm/07/c11/pdf/tm7-c11.pdf

Ratton, P., Secco, H., \& da Rosa, C. A. 2014. Carcass permanency time and its implications to the roadkill data. European Journal of Wildlife Research, 60(3), 543-546. DOI: 10.1007/s10344014-0798-Z

Roedenbeck, I. A., Fahrig, L., Findlay, C. S., Houlahan, J. E., Jaeger, J. A. G., Klar, N., Kramer-Schadt, S., \& van der Grift, E. A. 2007. The Rauischholzhausen agenda for road ecology. Ecology and Society, 12(1), 11.
Rosa, C. A. da, \& Bager, A. 2012. Seasonality and habitat types affect roadkill of neotropical birds. Journal of Environmental Management, 97(1), 1-5. DOI: 10.1016/ j.jenvman.2011.11.004

Rytwinski, T., \& Fahrig, L. 2011. Reproductive rate and body size predict road impacts on mammal abundance. Ecological Applications, 21(2), 589-600. DOI: 10.1890/10-0968.1

Rytwinski, T., van der Ree, R., Cunnington, G. M., Fahrig, L., Findlay, C. S., Houlahan, J., Jaeger, J. A. G., Soanes, K., van der Grift, E. A. 2015. Experimental study designs to improve the evaluation of road mitigation measures for wildlife. Journal of Environmental Management, 154, 48-64. DOI: 10.1016/ j.jenvman.2015.01.048

Santos, S. M., Carvalho, F., \& Mira, A. 2011. How long do the dead survive on the road? Carcass persistence probability and implications for road-kill monitoring surveys. PloS One, 6(9), e25383. DOI: 10.1371/journal.pone.0025383

Seiler, A., \& Helldin, O. J. 2006. Mortality in wildlife due to transportation. In: J. Davenport \& J. L. Davenport (Eds.), The ecology of transportation: Managing mobility for the environment. pp. 165-189. Houten: Springer Netherlands.

Slater, F. M. 2002. An assessment of wildlife road casualties - the potential discrepancy between numbers counted and numbers killed. Web Ecology, 3(1), 33-42. DOI: 10.5194/we-3-33-2002

Snow, N. P., Porter, W. F., \& Williams, D. M. 2015. Underreporting of wildlife-vehicle collisions does not hinder predictive models for large ungulates. Biological Conservation, 181, 44-53. DOI: 10.1016/j.biocon.2014.10.030

Stokes, J. 2015. What transportation agencies need in environmental impact assessments and other reports to minimise ecological impacts. In: R. van der Ree, D. J. Smith \& C. Grilo (Eds.), Handbook of road ecology. pp. 43-50. West Sussex: John Wiley \& Sons.

Teixeira, F. Z. 2015 Trilhando caminhos para avaliar padrões espaciais de mortalidade e fragmentação em rodovias. Programa de Pós-Graduação em Ecologia da Universidade federal do Rio Grande do Sul. p. 214. Retrieved from http:// hdl.handle.net/10183/131935

Teixeira, F. Z., Coelho, A. V. P., Esperandio, I. B., Kindel, A. 2013a. Vertebrate road mortality estimates: effects of sampling methods and carcass removal. Biological Conservation, 157, 317-323. DOI: 10.1016/j.biocon.2012.09.006

Teixeira, F. Z., Coelho, I. P., Esperandio, I. B., Oliveira, N. R., Peter, F. P., Dornelles, S. S., Delazeri, N. R., Tavares, M., Martins, M. B., Kindel, A. 2013b. Are road-kill hotspots coincident among different vertebrate groups? Oecologia Australis, 17(1), 36-47. DOI: 10.4257/oeco.2013.1701.04

Teixeira, F. Z., Coelho, I. P., Lauxen, M., Esperandio, I. B., Hartz, S. M., Kindel, A. 2016. The need to improve and integrate science and environmental licensing to mitigate wildlife mortality on roads in Brazil. Tropical Conservation Science, 9(1), 34-42. DOI: 10.1177/194008291600900104

Tennøy, A., Kværner, J., \& Gjerstad, K. I. 2006. Uncertainty in environmental impact assessment predictions: The need for better communication and more transparency. Impact Assessment and Project Appraisal, 24(1), 45-56. DOI: 10.3152/147154606781765345 
Trombulak, S. C., \& Frissell, C. A. 2000. Review of ecological effects of roads on terrestrial and aquatic communities. Conservation Biology, 14(1), 18-30. DOI: 10.1046/j.15231739.2000.99084.x
Yoccoz, N. G., Nichols, J. D., \& Boulinier, T. 2001. Monitoring of biological diversity in space and time. Trends in Ecology \& Evolution, 16(8), 446-453. DOI: 10.1016/S01695347(01)02205-4

Submitted: 11 August 2016

Accepted: 28 November 2016 